\title{
Agroecologia como alternativa de produção no campo: um estudo de caso no assentamento João Batista II, em Castanhal - PA
}

\author{
Livia Silva Santos ${ }^{1}$, Leonardo Figueiredo de Souza ${ }^{2}$, Gilson da Silva Costa ${ }^{3}$
}

\begin{abstract}
Resumo: Objetiva-se neste trabalho refletir sobre a contribuição da agroecologia como forma de produção e de luta dos trabalhadores rurais que vivem no território do assentamento João Batista II em Castanhal/PA. Para tanto, adotamos como procedimento metodológico a elaboração de entrevistas com base em roteiro semiestruturado na perspectiva de Brumer et. al (2008) e conversas informais com as (os) agricultoras (es). Desse modo, observou-se, que uma característica marcante nos discursos dos entrevistados foi de que, para eles a agroecologia é muito mais do que uma técnica produtiva ou uma ciência, pois envolve uma variedade de outras dimensões, além do manejo de um determinado agroecossistema, o que permite concluir que os assentados possuem o processo agroecológico conscientemente internalizados, compreendendo que a forma de produção agroecológica possibilita benefícios não somente para si, mas também para todo o contexto social e ambiental em que estão inseridos.
\end{abstract}

Palavras-chave: Movimento dos trabalhadores rurais sem terra. Agroecologia. Capitalismo.

Área Temática: Agroecologia. Sociologia rural. Desenvolvimento rural.

\section{Agroecology as an alternative production in the field: a case study in the João Batista II settlement, in Castanhal - PA}

\begin{abstract}
The objective of this work is to reflect on the contribution of agroecology as a form of production and struggle for rural workers who live in the territory of the João Batista II settlement in Castanhal / PA. To this end, we adopted as a methodological procedure the preparation of interviews based on a semi-structured script in the perspective of Brumer et. al (2008) and informal conversations with farmers. Thus, it was observed that a striking feature of the interviewees' speeches was that, for them, agroecology is much more than a productive technique or a science, as it involves a variety of other dimensions, in addition to the management of a given agroecosystem, which allows us to conclude that the settlers have the agroecological process consciously internalized, understanding that the form of agroecological production allows benefits not only for themselves, but also for the entire social and environmental context in which they are inserted.
\end{abstract}

Keywords: Landless rural workers movement. Agroecology. Capitalism.

\section{Agroecología como producción alternativa en el campo: un caso de estudio en el asentamiento João Batista II, en Castanhal - PA}

Resumen: El objetivo de este trabajo es reflexionar sobre el aporte de la agroecología como forma de producción y lucha de los trabajadores rurales que viven en el asentamiento João Batista II en Castanhal / PA. Para ello, adoptamos como procedimiento metodológico la elaboración de entrevistas basadas en un guión semiestructurado

\footnotetext{
${ }^{1}$ Mestranda em Agriculturas Familiares e Desenvolvimento Sustentável pela Universidade Federal do Pará (MAFDS/UFPA). Membro do Grupo de estudos, pesquisa e comunicação Natureza, desenvolvimento e sustentabilidade na Amazônia (NADESA).

${ }^{2}$ Graduando em Ciências Sociais pela Universidade Federal do Pará. Membro do Grupo de estudos, pesquisa e comunicação Natureza, desenvolvimento e sustentabilidade na Amazônia (NADESA).

${ }^{3}$ Professor de Economia da Universidade Federal do Pará. Coordenador do Grupo de estudos, pesquisa e comunicação Natureza, desenvolvimento e sustentabilidade na Amazônia (NADESA).
} 
en la perspectiva de Brumer et. al (2008) y conversaciones informales con agricultores. Así, se observó que un rasgo llamativo en los discursos de los entrevistados fue que, para ellos, la agroecología es mucho más que una técnica productiva o una ciencia, ya que involucra una variedad de otras dimensiones, además de la gestión de una determinada. agroecosistema., lo que permite concluir que los pobladores tienen el proceso agroecológico conscientemente internalizado, entendiendo que la forma de producción agroecológica permite beneficios no solo para ellos mismos, sino también para todo el contexto social y ambiental en el que se insertan.

Palabras clave: Movimiento de trabajadores rural sin tierra. Agroecología. Capitalismo.

\section{INTRODUÇÃO}

O período pós-segunda guerra mundial foi marcado por grandes transformações de ordens econômicas, políticas e sociais que afetaram grande parte do mundo. Neste período, havia no Brasil uma discussão em torno da questão agrária e da agricultura. De um lado, com um cunho teórico e político um grupo que defendia a reforma agrária, com enfoque a produção de alimentos sem utilização de agrotóxicos e de outro um discurso de modernização conservadora, capitalista, excludente da agricultura. Com o golpe militar de 1964 consolidou-se o projeto de modernização da agricultura capitalista por meio da produção de alimentos com a utilização de agrotóxicos , com o discurso dominante do agronegócio e dos grandes latifúndios (DELGADO, 2010).

Nos últimos 50 anos, esse modo de produção interconectado com a economia internacionalizada, acarretou mudanças de ordem sociais, econômicas, políticas, técnicas e ambientais no meio rural, acirando ainda mais a concentração fundiária. Um mecanismo fundamental neste processo foi a incorporação e difusão do pacote tecnológico (insumos químicos, sementes geneticamente modificadas, irrigação, mecanização), advindo da "Revolução Verde" que propôs o fim da fome, que resultou a industrialização da agricultura brasileira e, consequentemente, o aumento da produção agropecuária etc. Entretanto, não foi solucionado problema da fome no mundo que se dispunha resolver, o aumento da exploração da mais-valia dos trabalhadores e a concentração do capital em suas várias frações, sobretudo a comercial, a agroindustrial, a industrial, a financeira e o fundiário, conjugado ao ilusionismo tecnológico, bem como a uma base ideológica de valorização do progresso (PEREIRA, 2012).

A forma de agricultura implantada pela lógica do agronegócio, com valorização do progresso, causa a perda dos saberes tradicionais do camponês, pois organiza o seu território voltado para a produção de mercadorias, direcionada para o interesse dos grupos econômicos financeiros em busca do lucro desenfreado e reprodução do capital ilimitado, não tem o mínimo pudor em sacrificar vidas humanas. Enquanto o campesinato organiza o seu território para realização de sua existência, necessitando desenvolver todas as dimensões territoriais juntamente com as relações sociais existentes. Esta diferença se expressa na paisagem, a paisagem do território do agronegócio é homogênea, focada na monocultura é caracterizada pela pouca presença de gente no território. Adiversidade de elementos que compõem a paisagem do território camponês é caracterizada pela maior presença de pessoas, porque é neste e deste espaço que elas constroem suas existências, formas de relações sociais e produzem alimentos (FERNANDES, 2006). 
Em contraposição à lógica industrial do agronegócio, alguns grupos sociais passaram a internalizar novos valores e princípios epistemológicos passando a incorporar ao centro de seu ideário conceitos como o de respeito e resgate da agricultura camponesa, bem como as diretrizes da Agroecologia buscando alcançar sustentabilidade ecológica e equidade social. Entre as diferentes ações, destacamos a mobilização social dos produtores rurais excluídos e em processo de exclusão e as ricas experiências de luta articuladas contra a lógica hegemônica destruidora do capital e contra as ações dos poderes públicos constituídos. Neste grupo destacam-se os sem terras, cujas ações de luta e resistência resulta na recriação camponesa nos assentamentos ${ }^{4}$ rurais e, a partir de experiências de cooperativização e coletivização, apontam novas possibilidades de desenvolvimento rural (GONÇALVES, 2008).

Com 30 anos de existência, o Movimento dos Trabalhadores Rurais Sem Terra (MST), ao longo de sua trajetória foi se consolidando como um ator político de organização combativa, de enfrentamento aos interesses capitalistas do campo, de luta pela terra. Recentemente, vem assumindo a defesa de uma agricultura ecológica contrária ao uso de agrotóxicos e da transgenia, com isso tem buscado uma forma de produção mais racional que permita a migração produtivista/tecnicista para outro baseado numa perspectiva mais agroecológica com enfoque na sustentabilidade ecológica, sustentabilidade humana no campo e na equidade social, que contribua para que as famílias tenha garantia do auto sustento, assim como alternativa de desenvolvimento sustentável aos assentamentos de Reforma Agrária (BORSATTO, CARMO, 2013) .

De acordo com Gliessman (2001), a agricultura sustentável é aquela que reconhece a natureza sistêmica do agroecossistema, buscando o equilíbrio e a equidade, preocupando- se com a saúde ambiental, justiça social e viabilidade econômica, entre diferentes setores da população, incluindo povos e gerações diferente. Para Altieri (2002), a agricultura sustentável refere-se à produção de alimentos que se utilize de tecnologias de manejo ecológicas para que haja rendimentos duráveis, à longo prazo, o que requer a otimização do sistema como um todo e não apenas o rendimento máximo de qualquer produto específico.

A partir de estudos agronômicos, encontramos correntes alternativas ao modelo da Revolução Verde, que propõem um novo padrão de desenvolvimento agrícola mediante ao manejo ecologicamente adequado dos recursos naturais e a correta seleção de tecnologias, visando à sustentabilidade, estabilidade, produtividade e equidade social. Como síntese do pensamento alternativo, a Agroecologia recolhe as contribuições de diferentes fontes teóricas com um novo paradigma científico que pretende responder questões emergentes deste início de novo milênio (CAPORAL, COSTABEBER, 2000).

AAgroecologia é, de cordo com Altieri (2002), a ciência que busca restabelecer a produção agrícola com um entendimento mais profundo da natureza dos agroecossistema, enfatizando a inter-relações e os sinergismos entre seus componentes bióticos e abióticos, com aplicação de conceitos e princípios ecológicos para o desenvolvimento de uma agricultura mais sustentável e autossuficiente. Ainda acordo com isso, Costa (2006) entende que 
a agroecologia pode ser considerada uma possibilidade para a construção de um desenvolvimento melhor da relação entre o homem e a natureza, onde seria possível unir a produção de alimentos, conservação ambiental e reprodução social, pois, para este autor a agroecologia surgiu como a ciência que permitiria a humanidade a possibilidade de concretização de uma agricultura realmente saudável e sustentável. (COSTA, p. 109, 2006)

Entre os grupos que tem acumulado experiência na prática de produção agroecológica a nível nacional destacamos o Movimento dos Trabalhadores Rurais Sem Terra - MST, cujas ações coletivas tem tido como foco a recriação camponesa nos assentamentos rurais mediante a materialização de experiências de cooperativização e coletivização, as quais apontam para novas possibilidades de desenvolvimento rural sustentável. Nesse sentido, faz-se necessário investigar como vem se configurando a produção Agroecológica no assentamento João Batista II.

O assentamento João Batista II está localizado no nordeste paraense em Castanhal/PA e tem acumulado, ao longo dos anos, experiências significativas com enfoque agroecológico em lotes dos assentados da reforma agrária, especialmente a experiência existente no Sistema Agroecológico, o qual é desenvolvido por uma das lideranças mais antigas do Assentamento.

Trazer para o debate o paradigma da Agroecologia significa reafirmar a relevância de um modelo de produção que se opõe a lógica hegemônica excludente da agricultura capitalista representada pelo agronegócio, pois ela emerge da construção coletiva e popular de um projeto de desenvolvimento sustentável dos trabalhadores e trabalhadoras do campo

\section{OBJETIVO}

Desse modo, o presente trabalho objetiva refletir sobre a contribuição da agroecologia como forma de resistência e de luta dos trabalhadores rurais que vivem no território do assentamento João Batista II em Castanhal/ PA, mediante a lógica hegemônica de expropriação da natureza desenvolvida, sobretudo, pelo agronegócio.

\section{METODOLOGIA}

A origem deste trabalho encontra-se no exponencial avanço da agroecologia no Brasil e no mundo, provocando mudanças nas formas de relação entre sociedade e natureza, possibilitando, mesmo com seus limites, uma outra perspectiva de produção no campo, como é o caso da experiência que tem ganhado corpo nos últimos tempos nos assentamentos do Movimento dos Trabalhadores Rurais Sem Terra (MST), ao qual o Assentamento João Batista II integra.

A partir do convite para visitar o referido assentamento no ano de 2019, notou-se que ali estava em curso um processo de transição agroecológica, o que despertou a curiosidade dos autores deste trabalho para compreender como os atores deste processo o percebiam? Quais as contribuições que a agroecologia estava 
proporcionando para o assentamento? Essas e outras questões, deram inicio a esta investigação que ainda está em andamento. Isto é, as informações apresentadas neste trabalho, não são a totalidade do processo, que ainda está inconcluso, nem a pesquisa finalizada.

Para alcançar os objetivos deste trabalho e responder as perguntas norteadoras da investigação, inicialmente foi feito um levantamento bibliográfico a partir dos principais autores da agroecologia para fundamentar a pesquisa e compreender quais são suas principais diretrizes. Posteriormente, em retorno ao assentamento, os sujeitos foram convidados a participar aleatória e voluntariamente do presente estudo. Em seguida foi aplicado o termo de consentimento livre e esclarecido e garantido o sigilo absoluto da participação, sem qualquer identificação dos indivíduos. Inclusive, optamos por não os identificar para que sua segurança não fique comprometida.

Aceitaram participar do estudo 3 agricultores assentados, entre estes, 2 homens e 1 mulher, os quais responderam roteiros contendo perguntas abertas que visaram obter informações espontâneas a partir das reflexões dos entrevistados, onde eles eram livres para expressar e dar opiniões a respeito de como vem se consolidando o discurso Agroecológico dentro do assentamento. As entrevistas foram realizadas em agosto de 2019, na cidade de Castanhal-PA, no assentamento João Batista II.

Para a realização deste trabalho, procedeu-se uma pesquisa qualitativa, que procura responder a duas questões elementares: "como" e "por quê" um fenômeno ocorre num dado contexto (CAMPOMAR, 1991; GIL 2008). Como ferramenta, utilizamos entrevistas com base em roteiro semiestruturado na perspectiva de Brumer et. al (2008) e conversas informais com as (os) agricultoras (es), além da observação local.

Através dessas entrevistas é que foi possível ter acesso as percepções dos assentados sobre as contribuições da Agroecologia para a produção e reprodução da vida social no assentamento e as comparamos com as perspectivas dos principais teóricos da agroecologia, o que possibilitou reflexões interessantes que estão presentes ao longo deste escrito.

Na identificação dos entrevistados no decorrer deste trabalho, optamos por utilizar nomes fictícios para garantir o sigilo em prol de sua segurança, uma vez que o assentamento é marcado por uma longa história de conflitos com fazendeiros e com o Estado. Desse modo, para os homens demos os nomes de Carlos e Ernesto e para a mulher demos o nome de Rosa.

\section{Aspectos históricos e políticos do assentamento João Batista II}

Em 03 de maio de 2000, após décadas de lutas e conflitos, ocorreu a desapropriação ${ }^{5}$ de terra que deu origem ao assentamento João Batista II (mapa 01), que está localizado na cidade de Castanhal, no estado do Pará, onde vivem 153 famílias e que possui uma área total de 1.761,7600 hectares com capacidade para abrigar 157 famílias no total de acordo com o INCRA (Instituto Nacional de Colonização e Reforma Agrária) ${ }^{6}$. 


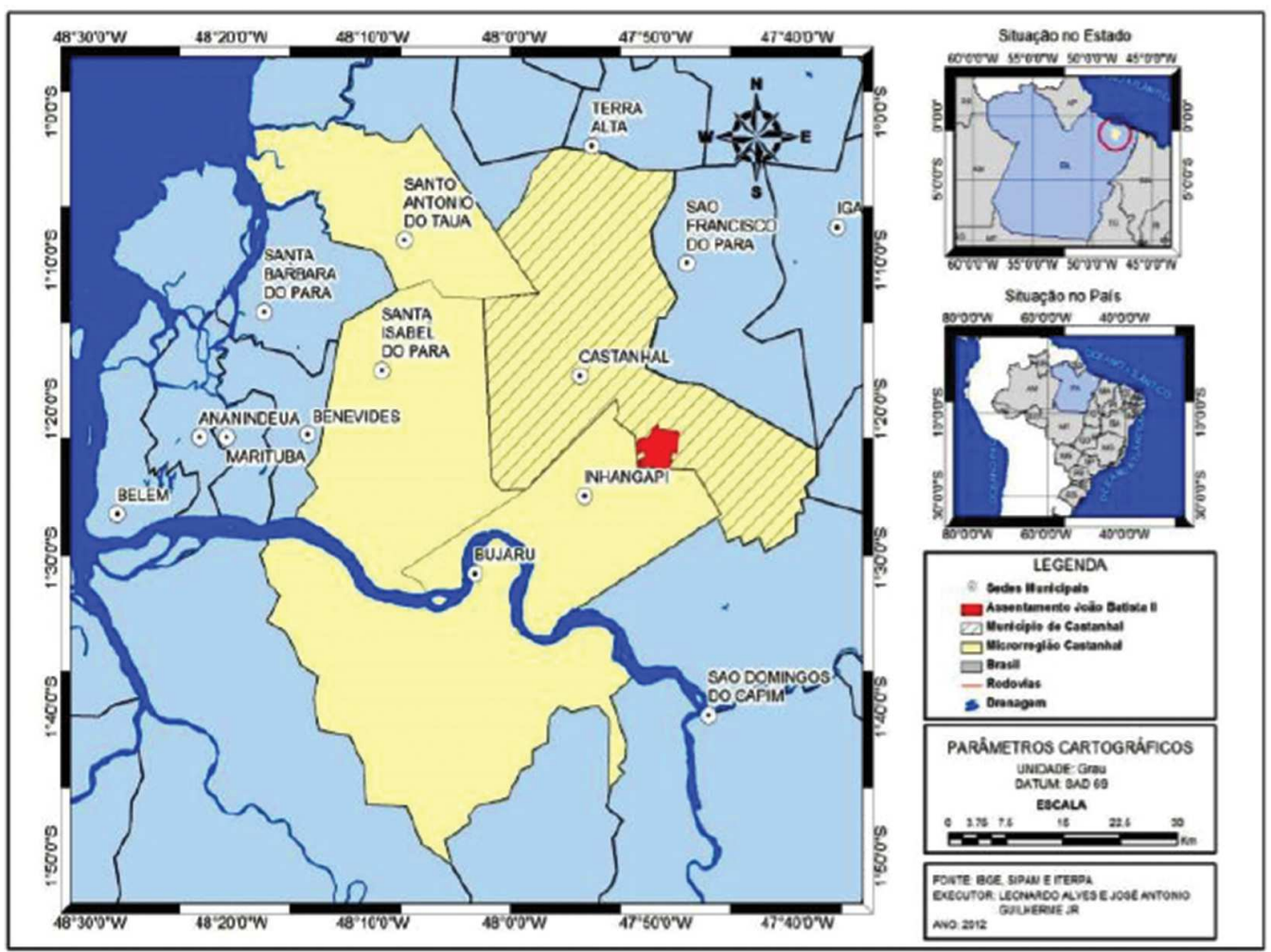

MAPA 01 - Localização do Município de Castanhal - PA e do assentamento João Batista II. Fonte: IBGE/INTERPA, 2005.

A área do assentamento é limitada pelos rios Inhangapi, Patauateua e Igarapé Bacuri, com a ocorrência de essências florestais como Matamatá, Anani, Tatajuba, Sapucaia, Virola, Castanha do Pará, Andiroba e outras. O principal meio de acesso a fazenda é pela BR-316, num ramal que fica distante 8 quilômetros da rodovia, à 68 quilômetros de Belém e a 12 quilômetros do centro de Castanhal.

De acordo com Mendonça (2004) durante as décadas de 20 e 30 do século XX, na área do assentamento predominava uma grande mata primária, onde se praticava o extrativismo vegetal. Porém, com a chegada dos colonos, as roças de arroz, mandioca, feijão e milho começavam a ocupar os lugares que eram das grandes árvores. Ainda de acordo com este autor, durante os anos de 1950 e 1960 as terras pertenciam ao Estado, apesar de serem ocupadas por colonos.

De acordo com Nascimento (2017), até meados da década de 1960 as relações sociais estabelecidas na área do assentamento se davam em graus parentais, que se espalharam logo após a chegada dos fazendeiros na região, especialmente com a chegada de Domingo Rangel, o ultimo dono da fazenda Tanari. Sua presença era marcada por muitos conflitos com os que viviam nas redondezas e, em muitos casos, esses conflitos resultavam na morte dos que se opunham a ele. Com o asfaltamento da BR-316 nas décadas de 1970 e 1980 pelos Militares e o incentivo liberado pelo governo, a relação entre fazendeiros e políticos foi se estreitando, culminando na expropriação das terras dos colonos e as transformando em uma grande propriedade. (MENDONÇA, 2004) 
Com a hipoteca da fazenda, outros fazendeiros da região assediavam constantemente os ocupantes na tentativa de comprar a área. O que fez com que houvesse um clima de insegurança de grandes proporções quando no sétimo dia de acampamento um integrante do MST foi baleado em uma emboscada próximo a fazenda (NASCIMENTO, 2017). Este acontecimento provocou uma reorganização dos assentados, fazendo com que tomassem a decisão estrategicamente de transferir o acampamento para as proximidades da entrada da fazenda, onde poderiam controlar a entrada e saída de pessoas e impedir, portanto, novos ataques. A partir desta reorganização espacial das famílias, houve a exigência de ocupação total da Fazenda, em que foi exigida a retirada do gato e a desocupação da propriedade por parte dos funcionários. (GUILHERME JÚNIOR, 2013).

Em maio de 1999 foi publicado no Diário Oficial da União, a desapropriação da fazenda Tanari. Todavia, apenas em outubro do mesmo ano as famílias mudaram-se para a área e iniciaram a construção das primeiras casas e plantação das primeiras roças, objetivando uma produção de subsistência. Esta área foi então subdividida em quadras destinadas às casas, e foi feita a localização de ruas, igreja, escola e posto de saúde, resultando no modelo de agrovila idealizado pelos assentados com auxílio do MST (NASCIMENTO, 2017).

Todavia, como apontam Mendonça (2004) e Guilherme (2013) a posse da terra não lhes garantiu muita qualidade de vida, a precariedade ainda era presente na vida dessas famílias recém assentadas, pois dependia somente de doações do INCRA.

Segundo Nascimento:

essa precarização das condições de vida dos assentados se estende até os dias atuais, apesar dos avanços que a comunidade apresenta, desde a estrutura das moradias e a produção na terra, até os acessos a educação e a saúde. As opções de trabalho, principalmente no que se refere a juventude, se restringem ao trabalho no lote (próprio e de outros assentados), a prestação de serviços domésticos à outras famílias da comunidade, e o arrendamento de terras para os fazendeiros da região. Essa precarização se dá em razão também ausências de políticas sociais que a comunidade enfrenta, ou seja, da não atuação do poder público no que diz respeito ao saneamento básico, a assistência efetiva a saúde e melhores condições de vida (NASCIMENTO, 2017, p. 76).

Mediante a estas precarizações tratadas por Mendonça, Guilherme e Nascimento, as famílias do assentamento procuram outras possibilidades para sobreviver e tentar garantir uma melhor qualidade de vida como por exemplo, a busca de uma produção agroecológica, a construção de cooperativas e a luta política através do MST, como apontam estudos como o de Costa e Rocha (2019), dentre muitos outros.

\section{RESULTADOS E DISCUSSÃO}

Durante a pesquisa, observamos que em relação as perguntas não houveram muitas divergências nas respostas dos entrevistados, mesmo tendo entrevistado dois homens e uma mulher, em relação a contribuição da agroecologia para o assentamento as respostas foram muito próximas. Dito isto, a partir das entrevistas, podemos 
apontar que uma característica marcante nos discursos dos entrevistados foi de que, para eles a agroecologia é muito mais do que uma técnica produtiva ou uma ciência, pois envolve uma variedade de outras dimensões, além do manejo de um determinado agroecossistema. Sendo constatado durante a realização da pesquisa, de acordo com os depoimentos dos entrevistados que:

\begin{abstract}
agroecologia vai muito além de uma forma de produção de alimentos saudáveis, ela corresponde a uma forma de reprodução social no campo, a nós agricultores assentados, onde criamos a nossa própria forma de existência (CARLOS - membro do MST e assentado do João Batista II, 2019).

é um modo de vida em que a terra e suas relações com a dimensão humana, econômica e espiritual são retomadas como elemento pra um outa forma de sociabilidade (ERNESTO - membro do MST e assentado do João Batista II, 2019).
\end{abstract}

Esses relatos vão de acordo com o que Caporal et al. (2011) aponta em princípios e perspectivas da agroecologia ao argumentar que como ciência integradora a agroecologia se nutre não só dos saberes reconhecidamente acadêmicos, mas também de conhecimentos tradicionais e empíricos dos agricultores e dos demais atores sociais envolvidos em processos de desenvolvimentos rurais, isso porque ela incorpora o potencial endógeno, que é fundamental para a agroecologia pois envolver os aspectos socioculturais e agroecossistêmicos que formam as bases estratégicas de qualquer desenvolvimento rural que visem alcançar crescentes graus de sustentabilidade. Ainda em consonância com isso, o estudo realizado por Borsatto e Carmo (2013), aponta que através da agroecologia o agricultor deixa de ser visto como um mero objeto de análise, e passa a ser o sujeito que (re)cria sua própria existência, ao incorporar em seu ideário conceitos como o respeito e resgate da agricultura camponesa, a qual supera a lógica excludente e insustentável do capitalismo ${ }^{7}$; a compreensão do balanço trabalhoconsumo por oferecer respostas práticas para que os agricultores possam garantir sua reprodução social em seu território. Dessa forma; assumido o protagonismo na luta pelo direito de existir e reexistir no seu território por meio da agroecologia.

Vale ressaltar que o sistema de produção agroecológica visa à produção de alimentos ecologicamente sustentável, economicamente viável e socialmente justo, capaz de integrar o homem ao meio ambiente (COSTA, 2006). A produção sustentável de alimentos possibilita a produção de gêneros alimentícios saudáveis, de qualidade para a subsistência dos pequenos agricultores que vivem em regime da agricultura camponesa promovendo a geração de renda com a venda da produção do excedente. A produção agroecológica sustentável também é uma forma de atuação de pequenos agricultores rurais, que trabalham de forma articulada, com uma visão econômica e social que proporcione qualidade de vida e que estimule o manejo sustentável, com o mínimo impacto ambiental (SOUZA, 2014).

Quando questionamos se a forma de produção que eles promovem é agroecológica, constatamos que o lote ainda está em transição, pois já utilizam algumas tecnologias alternativas pautadas na agroecologia, segundo declarou o entrevistado: 
De certo modo, sim. Ainda não há no meu lote um manejo totalmente pautado nos princípios agroecológicos. Mas já temos algumas experiências neste sentido, a exemplo de a adubação orgânica das culturas perenes introduzidas no lote em uma experiência de SAF' $\mathrm{S}^{8}$, adubação verde em determinadas partes do lote, cobertura orgânica do solo para a ciclagem natural de nutrientes, assim como a introdução de plantas companheiras no sistema (CARLOS - membro do MST e assentado do João Batista II, 2019).

Estou em transição, produzindo mudas frutíferas e horta. Tenho um SAF integrado a criação de pequenos animais (ERNESTO - membro do MST e assentado do João Batista II, 2019).

A transição agroecológica é uma forma de praticar a agricultura com base em tecnologias sustentáveis menos agressivas ao meio ambiente, mais justa socialmente e assentada em novos valores que incorporem a dimensão ética na apropriação econômica dos recursos naturais, não apresenta nenhuma garantia de sua realização no curto prazo, garantindo a sustentabilidade ambiental onde a ecologia e a economia se entreveram cada vez mais nos planos local, regional, nacional e mundial até formar uma rede concatenada de causas e efeitos (COSTABEBER, 1999).

Da mesma forma Leff (2002) sustenta que a Agroecologia é uma ciência com limites teóricos bem definidos que busca integrar o saber de diferentes áreas do conhecimento com o objetivo de propor um encaminhamento que respeite as condicionantes ambientais na agricultura. A agroecologia constitui-se em um regaste de conhecimentos sistematizados, baseados em técnicas e saberes tradicionais dos pequenos agricultores rurais, que incorporam princípios ecológicos e valores culturais às práticas agrícolas que, com o tempo, foram descolonizadas e aculturalizadas pela lógica de produção do agronegócio e da revolução verde.

No Pará a exploração criminosa dos recursos naturais pelo agronegócio, hidronegócio e mineralnegócio vem ganhando mais intensidade, prejudicando a sustentabilidade de territórios de comunidades tradicionais e trazendo sérias complicações em virtude do modelo insustentável de exploração que insiste em adotar práticas indevidas. A produção do agronegócio, por exemplo, se desenvolve na Amazônia com destaque para a criação de gado e agricultura de base capitalista como a monocultura, voltada exclusivamente para a exportação da produção.

A necessidade de pensar estratégias de enfrentamento ao desafio da exploração criminosa do agronegócio implica também a necessidade de pensar formas de resistência ao modelo de expansão da hegemonia do capital.

Quando questionados sobre a motivação em trabalhar com práticas agroecológicas, os entrevistados apontaram os benefícios voltados para sustentabilidade ambiental e para a saúde humana. Ao enfatizar que:

é preciso produzir pensando em saúde, tanto do trabalhador quanto da natureza. Nesse sentido, é propor a produção não enquanto alternativa, mas, sobretudo enquanto necessidade. É preciso romper com o modelo de produção convencional de queimada, de agrotóxicos, de "fertilização "artificial", de manejo que degrada, embora que a médio e longo prazo. Em virtude de o agricultor ter necessidades imediatas, a agroecologia não permite ser vista a priori enquanto alternativa econômica. Não dá pra radicalizar a priori como por exemplo nas culturas sazonais sendo o necessário artificializar com uso do NPK industrial (CARLOS - membro do MST e assentado do João Batista II, 2019). 
Satisfação em saber que os alimentos que estou consumindo são saudáveis para mim e minha família (ROSA - membro do MST e assentado do João Batista II, 2019).

A agroecologia dialoga com a proposta da Segurança Alimentar e Nutricional (SAN), que consiste na realização do direito de todos ao acesso regular e permanente a alimentos de qualidade, em quantidade suficiente, sem comprometer o acesso a outras necessidades essenciais, tendo como base práticas alimentares promotoras de saúde que respeitem a diversidade cultural e que sejam ambiental, cultural, econômica e socialmente sustentáveis. Esse direito só poderá ser viabilizado se houver garantia de que os alimentos serão produzidos em sistemas agrícolas sustentáveis (RIBEIRO et al., 2012).

De a acordo com o estudo realizado por Azevedo e Pelicioni (2011), o equilíbrio ambiental está intrinsecamente ligado ao conceito de saúde humana, e ao optar por práticas e princípios baseados na Agroecologia pode tornar-se instrumento na promoção da saúde ambiental. A adoção de práticas de base agroecológica na produção de alimentos prevê consequências ambientais positivas, como o aumento da fertilidade do solo, a promoção da qualidade de vida dos animais e seres humanos vivendo num ambiente isento de substâncias tóxicas, a manutenção da diversidade biológica da flora e da fauna e o incremento da qualidade das águas, do solo e do ar.

Em relação as mudanças que agroecologia tem provocado no cotidiano do assentamento de acordo com os sujeitos entrevistados refere-se a harmoniosa relação entre ser humano/ natureza, humano/humano a expor que:

\footnotetext{
A relação de proximidade da terra/ humano, relação entre as pessoas, na alegria que a gente ver no camponês a cada passo dado na unidade entre agricultores que vivem a experiência (ERNESTO membro do MST e assentado do João Batista II, 2019).

Mudanças ainda tímidas, porém, significativas visto que várias famílias já possuem agroquintais, SAFs. No PA atualmente vem ocorrendo significativa socialização de saberes presente nas trocas de experiências, a exemplo das atividades desenvolvidas por meio do viveiro de mudas coletivo presente no PA, o trabalho em equipe, a proposta de multiplicação das espécies a serem introduzidas nos agroecossistemas das famílias (CARLOS - membro do MST e assentado do João Batista II, 2019).
}

Os saberes populares resultam de uma relação de sinergismo entre homem/natureza, na qual a terra possui valor social, que constrói a essência do homem no trato com a natureza, para produzir alimentos e o bem viver. De acordo com De Mari et al. (2017) na agroecologia os saberes populares se somam na construção de um novo paradigma produtivo no campo, baseado no valor de uso social da terra, em contraponto com a mera lógica do mercado.

Segundo Leff (2002), as práticas com enfoque na agroecologia recuperam dos saberes tradicionais, a um passado no qual o humano era dono do seu saber, a um tempo em que seu saber marcava um lugar no mundo, à época dos saberes próprios. 
Segundo, Silva (2007) os territórios camponeses são exemplos da recriação de relações sociais não capitalistas entre a natureza/homem, havendo o resgate do reconhecimento da importância do saber tradicional dos povos rurais no manejo dos ecossistemas para a perspectiva de sua sustentabilidade a longo prazo.

De acordo com o relato dos entrevistados, o que marca o debate da agroecologia no assentamento é:

uma nova forma de vida que dá ao ser humano uma nova sociabilidade (ERNESTO - membro do MST e assentado do João Batista II, 2019).

uma alimentação saudável, ausência do agrotóxico, preservação da natureza e a própria relação da natureza e o homem (ROSA - membro do MST e assentado do João Batista II, 2019).

Os saberes populares resultam das relações harmoniosa entre homem/natureza, na qual a terra possui valor social, que constrói a essência do homem no trato com a natureza, para produzir alimentos e o bem viver. Aqui, os saberes populares se somam na construção de um novo paradigma produtivo no campo, baseado no valor de uso social da terra, em contraponto com a mera lógica do mercado capitalista (DE MARI et al., 2017).

Segundo os sujeitos entrevistados o processo de formação e informação do conhecimento da agroecologia dentro do assentamento ocorre por meio de estudos, debates, troca de saberes e experiencias quando diz que:

através de cursos, feiras agroecológicas onde ocorre a roda de conversa para que haja a troca de saberes o que é de suma importância para disseminação de forma de produção com base na agroecologia e por meio do debate de artigos estudados (CARLOS - membro do MST e assentado do João Batista II, 2019).

através de cursos, experiências, debates na comunidade, feiras agroecológicas (ERNESTO - membro do MST e assentado do João Batista II, 2019).

através de estudos em oficinas que acontecem em lotes agrícolas que já possuem experiência com essa prática (ROSA - membro do MST e assentado do João Batista II, 2019).

Caldart (2004) sustenta que o Movimento dos Trabalhadores Sem Terra (MST) em conjunto com outros movimentos e organizações sociais do campo, desde o final da década de 1990, vêm demarcando espaços, disputando projetos de sociedade e de desenvolvimento rural, resistindo e fazendo oposição ao modelo de produção rural historicamente vinculado ao paradigma hegemônico de sociedade tão defendida pela classe dominante.

Tal paradigma, ao valorizar o lucro da produção obtido pela força de trabalho deslegitima outros elementos inerentes a dignidade da pessoa humana como o reconhecimento e valorização da cidadania, do direito a terra e produzir na terra, das relações sociais construídas na relação com os outros sujeitos, da cultura, dos saberes e da identidade dos sujeitos do campo que se constrói na relação com o seu território e no compartilhamento de experiências coletivas (HAGE, 2005; BRANDÃO, FERREIRA, 2011). 
A pesquisa realizada por Lopes et al. (2013) no movimento agroecológico da zona Mata (MG) constatou que o compartilhamento de saberes tem contribuído positivamente para o fortalecimento e construção da agroecologia, já que por meio dessa troca gera o acumulo de aprendizagem coletiva, no qual as práticas dos eventos anteriores influenciam e, ao mesmo tempo, se aprimoram na construção do próximo encontro.

\section{CONCLUSÕES}

Conforme os resultados obtidos neste estudo, constatou-se que os assentados possuem o processo agroecológico conscientemente internalizado, uma vez que o compreendem e o percebem como uma possibilidade produtiva diante do modelo predatório de produção hegemônico do agronegócio, compreendendo que a forma de produção agroecológica possibilita benefícios não somente para si, mas também para todo o contexto social e ambiental em que estão inseridos. Além disso, destacam que ganhos financeiros não são os principais objetivos desse processo, mas, sim, a consequência deste esforço valorizando fatores sociais e ambientais no território existente, o que nos convida para refletir também não só sobre a forma de produção, mas também sobre outro aspecto central que se relaciona com ela, que são os objetivos finais desta produção.

Nesse sentido, os compromissos ambientais do MST ultrapassam meramente o uso da terra e incorporam a vida real, a cultura, introduzindo uma nova forma de relação entre os assentados, sustentada pela perspectiva do Bem Viver. Além disso, esses atores conseguem unir a ciência, acompanhada, obviamente, da prática na produção com a militância política do supracitado movimento, trazendo isso como um outro aspecto importante para a agroecologia.

\section{NOTAS}

${ }^{4}$ Para o Instituto Nacional de Colonização e Reforma Agrária (INCRA) o assentamento rural é entendido como um conjunto de unidades agrícolas independentes entre si, constituídas pelo INCRA onde inicialmente existia um imóvel rural que pertencia a um único indivíduo.

${ }^{5} \mathrm{E}$ a data da comissão coletiva de posse foi dada no dia 24 de novembro de 2000, estando registrado no CRI: $\mathrm{n}^{\text {o }} 44$ fls, 145 do livro 2-A-Castanhal-PA(INCRA, 200, p. 5)

${ }^{6}$ INCRA. Projetos de Reforma Agrária Conforme Fases de Implementação. Disponível em: assentamentosgeral.pdf (www.gov.br). Acesso: 30 de abril de 2021.

${ }^{7}$ Ver a tese de doutorado A alta modernidade e a revolução socioambiental: indivíduo e coletividade na reprodução sociometabólica do desenvolvimento e da sustentabilidade na Amazônia (2009) de Gilson da Silva Costa.

${ }^{8}$ Sistema Agroflorestal - SAF compreende a um sistema de plantio de natureza sustentável, sendo ainda muito utilizado na recuperação de uma floresta.

\section{REFERÊNCIAS}

ALTIERI, Miguel. Agroecologia: bases científicas para uma agricultura sustentável. Ed. Agropecuária Guaíba (RS), 2002.

AZEVEDO, Elaine de; PELICIONI, Maria Cecília Focesi. Promoção da Saúde, Sustentabilidade e Agroecologia: uma discussão intersetorial. Saúde e Sociedade, São Paulo, v. 20 n. 3, p. 715-729, 201. Disponível em: <https://www.scielo.br/pdf/sausoc/v20n3/16.pdf>. Acesso em: 02 Mar. 2019. 
BORSATTO, Ricardo Serra; CARMO, Maristela Simões do. A construção do discurso agroecológico no Movimento dos Trabalhadores Rurais Sem-Terra (MST). Revista de Economia e Sociologia Rural, Piracicaba, v. 51, n. 4, p. 645-660, 2013. Disponível em: <https://www.revistasober.org/article/doi/10.1590/ S0103-20032013000400002>. Acesso em: 03 Mar. 2018.

BORSATTO, Ricardo Serra; CARMO, Maristela Simões do. O MST e a Edificação de uma Proposta de Reforma Agrária Baseada em Princípios Agroecológicos. Retratos de Assentamentos, Araraquara, v. 16, n. 2, p. 221-243, 2013. Disponível em: <https://retratosdeassentamentos.com/index.php/retratos/article/view/ 148>. Acesso em: 05 Jan. 2019.

BRUMER, Anita; ROSENFIELD, Cinara L; HOLZMANN, Lorena ; SANTOS, Tania Steren dos. A elaboração de projeto de pesquisa em ciências sociais. In: GUAZZELLI, C. A.; PINTO, C.R. J. B. (org.). Ciências humanas: pesquisa e método. Porto Alegre: UFRGS, 2008. p. 125- 147.

CALDART, Roseli Salete. Elementos para construção do projeto político e pedagógico da educação do campo. Revista Trabalho Necessário, v. 2, n. 2, p. 1-16, 2004. Disponível em: <https://doi.org/10.22409/ tn.2i2.p3644>. Acesso em: 15 Jan. 2018.

CAPORAL, Francisco Roberto; COSTABEBER, José Antônio. Perspectivas para uma Nova Extensão Rural. Revista Agroecologia e Desenvolvimento Rural Sustentável. Porto Alegre, v. 1, n. 01, p. 16-37, 2000. Disponível em: <http://www.emater.tche.br/site/sistemas/administracao/tmp/1380710895.pdf>. Acesso em: 20 Abr. 2019.

CAPORAL, Francisco Roberto; COSTABEBER, José Antônio; PAULUS, Gervásio. Agroecologia: matriz disciplinar ou novo paradigma para o desenvolvimento rural sustentável. In: CAPORAL, F. R.; AZEVEDO, E. O. (org.). Princípios e Perspectivas da Agroecologia. Paraná: IFPR, 2011.

COSTA, Bruna Gonçalves; ROCHA, Geovane de Araújo. Agroecologia e produção orgânica: a atuação do MST em prol da sustentabilidade. In: Simpósio Brasileiro de Geografia Física Aplicada (XVIII SBGFA), ${ }^{\circ}$ XVIII, Fortaleza-CE, 2019, p. 1-9. Anais. Disponível em: <http://www.editora.ufc.br/images/imagens/pdf/ geografia-fisica-e-as-mudancas-globais/1508.pdf>. Acesso em: 29 Abr. 2021.

COSTA, Gilson da Silva. A alta modernidade e a revolução socioambiental: indivíduo e coletividade na reprodução sociometabólica do desenvolvimento e da sustentabilidade na Amazônia. 2009. 604 f.: Tese (doutorado) - Universidade Federal do Pará, Núcleo de Altos Estudos Amazônicos, Programa de PósGraduação em Desenvolvimento Sustentável do Trópico Úmido, Belém, 2009.

COSTA, Gilson da Silva. Desenvolvimento rural sustentável com base no paradigma da agroecologia. Belém, UFPA/NAEA, 2006.

COSTABEBER, José Antônio. Transição agroecológica: do produtivismo à ecologização. Sustentabilidade e cidadania: o papel da extensão rural. Porto Alegre: Emater/RS, p. 67-120, 1999.

DA TERRA, Comissão Pastoral, (CPT). Assassinatos no campo batem novo recorde e atingem maior número desde 2003. 16 de abril de 2018. Disponível em: <https://www.cptnacional.org.br/publicacoes/ noticias/cpt/4319-assassinatos-no-campo-batem-novo-recorde-e-atingem-maior-numero-desde-2003> . Acesso em: 13 Abr.2020. 
DE MARI, Cezar Luiz; TAVARES, Philippe Drumond Villas Boas; DAFONSECA, Valter Machado. Alimentos, saberes e educação para o "bem viver": os camponeses um passo adiante. Revista Eletrônica do Mestrado em Educação Ambiental, Rio Grande do Norte, v. 34, n. 3, p. 37-54, 2017. Disponível em: <https://doi.org/10.14295/remea.v34i3.7181>. Acesso em: 26 Nov. 2019.

DELGADO, Guilherme Costa. A questão agrária e o agronegócio no Brasil. Combatendo a desigualdade: o MST e a reforma agrária no Brasil. São Paulo: Editora UNESP, 2010.

FERNANDES, Bernardo Mançano. Os campos da pesquisa em educação do campo: espaço e território como categorias essenciais. In: MOLINA, Mônica (Org). A pesquisa em Educação do Campo. Brasília: Programa Nacional de Educação na Reforma Agrária, 2006.

FERREIRA, Fabiano de Jesus; BRANDÃO, Elias Canuto. Educação do campo: um olhar histórico, uma realidade concreta. Revista eletrônica de educação, v. 5, n. 9, jun./dez. 2011. Disponível em: <https:// educanp.weebly.com/uploads/1/3/9/9/13997768/ educao_do_campo_um_olhar_histrico_uma_realidade_concreta.pdf>.Acesso em: 24 Mai. 2014.

GLIESSMAN, Stephen R. Agroecologia: processos ecológicos em agricultura sustentável. Ed. da Univ. Federal do Rio Grande do Sul, UFRGS, 2001. ISBN 8570256035.

GONÇALVES, Sérgio. Campesinato, Resistência e Emancipação: o modelo agroecológico adotado pelo MST no Estado do Paraná. 2008.

GUILHERME JUNIOR. José Antônio. Reprodução camponesa em área de assentamento na Amazônia: um estudo no Assentamento João Batista II, Castanhal - Pará. 2013. Dissertação (Mestrado) - Universidade Federal do Pará, Instituto de Filosofia e Ciências Humanas, Programa de PósGraduação em Geografia, Belém, 2013.

HAGE, Salomão Mufarrej. Educação do campo na Amazônia: retratos de realidade das escolas multisseriadas no Pará. Belém: Gráfica e Editora Gutemberg Ltda, 2005.

KAGEYAMA; Angela. Desenvolvimento rural: conceito e medida. Cadernos de Ciência e Tecnologia, Brasília, v. 21, n. 3, p. 379-408, 2004. Disponível em: <https://seer.sct.embrapa.br/index.php/cct/article/view/ 8702>. Acesso em: 26 Mar. 2020.

LEFF, Enrique. Agroecologia e saber ambiental. Agroecologia e desenvolvimento rural Sustentável, Porto Alegre, v. 3, n. 1, p. 36-51, 2002. Disponível em: <https://www.projetovidanocampo.com.br/agroecologia/ agroecologia_e_saber_ambiental.pdf $>$.Acesso em: 04 Fev. 2017.

LOPES, Leandro Souza; CONTE, Guilherme Menezes; CRUZ, Nina Abigail Caligiorne, AMORIM JÚNIOR, Paulo César Gomes; CARDOSO, Irene Maria. Troca de saberes: vivenciando metodologias participativas para a construção dos saberes agroecológicos. Cadernos de Agroecologia, Porto Alegre, v. 8, n. 2, 2013. Disponível em: 〈http://revistas.aba-agroecologia.org.br/index.php/cad/article/view/14826>.

Acesso em: 23 Out. 2017.

MARX, Karl. O Capital: crítica da economia política. Livro 1. 2. ed. São Paulo: Boitempo, 2017.

MARX, Karl; ENGELS, Friedrich. Manifesto Comunista. 1. Ed. São Paulo: Boitempo, 2010. 
MENDONÇA, Yuri Vidal Santiago de. Assentamento rural: da propriedade privada à produção coletiva: o caso dos Pa's Cupiuba e João Batista II. 2004. Dissertação de Mestrado em Planejamento Urbano e Regional, UFRJ, 2004.

NASCIMENTO, Tábita Cristina Modesto. O tempo livre e a produção da existência da juventude do campo: um estudo com jovens estudantes do Assentamento João Batista II - PA. 2017. 145 f.: Dissertação (Mestre em Educação) - Universidade Federal do Pará, Instituto de Ciências da Educação, Programa de Pós-Graduação em Educação, Belém, 2017. Disponível em: <http://repositorio.ufpa.br/jspui/ handle/2011/9314>. Acesso em: 29 Abr. 2021.

OLIVEIRA, Roberto Cardoso de. O Trabalho do antropólogo: olhar, ouvir, escrever. In: O trabalho do antropólogo. 2. ed. São Paulo: Editora Unesp: paralelo15, 2000. p. 17-35.

PEREIRA, Mônica Cox de Britto. Revolução verde. Dicionário da Educação do Campo. Rio de Janeiro/ São Paulo: EPSJV/Expressão Popular, 2012, p. 685-691.

PETERSEN, Paulo; SILVEIRA, Luciano Marçal da; FERNANDES, Gabriel Bianconi; ALMEIDA, Silvio Gomes de. Método de Análise Econômico-Ecológica de Agroecossistemas. 1. Ed. Rio de Janeiro: ASPTA, 2017.

RIBEIRO, Silvana Maria; AZEVEDO, Elaine de; PELICIONI, Maria Cecília Focesi; BÓGUS, Cláudia Maria; PEREIRA, Isabel Maria Teixeira Bicudo. Agricultura urbana agroecológica-estratégia de promoção da saúde e segurança alimentar e nutricional. Revista Brasileira em Promoção da Saúde, Fortaleza, v. 25, n. 3 , p. 381-388, 2012. Disponível em: <https://periodicos.unifor.br/RBPS/article/view/2269>. Acesso em: 13 Abr.2020.

SILVA, Carlos Eduardo Mazzetto. Modo de apropriação da natureza e territorialidade camponesa: revisitando e ressigniûcando o conceito de campesinato. Revista Geografias. Belo Horizonte, v.3. p. 46-63, 2007.

SOUZA, Lidiane Karolyne Barbosa de. Produção agroecológica integrada e sustentável no Município de Mogeiro/PB. 2012. Trabalho de Conclusão de Curso (Graduação em Geografia) - Universidade Estadual da Paraíba, Secretaria de Educação a Distância - SEAD, 2012.

Submetido em: 03/03/2021 Aceito em: 22/04/2021. 